\title{
How the Assessment of Burden of Illness might change NICE Decisions: A Retrospective Analysis under Value-Based Pricing
}

\begin{abstract}
By Dimitra Alexiou*
Background: Value based price (VBP) is the price that reflects the value to patients, carers, society and the economy which delivers health benefits that exceed the health predicted to be displaced both elsewhere in the NHS and in the welfare economy, due to their additional cost. VBP is constituted of the the burden of illness (BoI), the cost of illness due to its severity and unmet need. It will replace the existing PPRS in September 2014. Objective: To address the question of how moving to a VBP system from the current Pharmaceutical Price Regulation Scheme (PPRS) might change selected old non-recommended and optimised NICE appraisal decisions dependent on the BoI, which considered to be a key driver of VBP. Methodology: Two classification measures were identified and used in order to categorise the selected diseases into higher, medium and lower burden. After a categorisation matrix was constructed, information about the BoI assessment along with the cost and clinical effectiveness of each disease were applied to the analysis so as to make recommendations of how NICE decisions might have changed under VBP and the BoI assessment. Results: A categorisation of the diseases into higher, medium, and lower burden was attempted and it was evident that the decisions differed with respect to the different measurement tool that were used. In some cases BoI played a trivial role into the assessment of NICE decisions due to the fact that clinical effectiveness was considered a more important factor. In other cases, where the ICER was bounded into the recommended range of $£ 20,000$ and $£ 30,000$, the nonrecommended or optimised decisions might change under VBP.
\end{abstract}

\section{Introduction}

The UK is home to a world class pharmaceutical industry in which five out of the top 75 selling medicines were discovered (Department of Health, 2010). The National Health Service (NHS) spent £11billion in 2010/2011 on pharmaceuticals, of which $£ 8$ billion was on branded drugs, representing around 13\% and 10\% respectively of their total budget (Department of Health, 2012),

\footnotetext{
*Analyst, Health Economics and Outcomes Research and Real World Evidence Solutions, UK.
} 
(Claxton et al., 2008). This however represents only a small proportion ( 3\%) of the global pharmaceutical market sales (Department of Health, 2010).

Since 1957, the prices of branded prescription medicines are regulated by the PPRS, which is usually renegotiated every five years. It is a "voluntary scheme" agreed between the Department of Health (DoH) and the Association of the British Pharmaceutical Industry (ABPI). The primary features of the PPRS are twofold. Firstly, it operates to regulate the prices of branded drugs which gives pharmaceutical companies freedom of pricing for new active substances upon launch but at the same time imposes restrictions on subsequent price increases (Thornton, 2007). Secondly, it controls through regulations the profits that pharmaceutical companies are allowed to make on their sales to the NHS by setting maximum and minimum levels of those profits (Department of Health, 2010).

The Office of Fair Trading (OFT) necessitated reform of the UK PPRS (Office of Fair Trading, 2007). The OFT report argued that the current scheme was not the best way of meeting the social goals and that profit and price controls fail to take into account the value to patients that the drug companies are producing. As a result, greater flexibility in pricing options were introduced in the 2009 PPRS which enabled drug companies to improve the value specific drugs offered to the NHS. These options took the form of Patient Access Schemes (PAS), tantamount to VBP, which offered discounts or rebates to reduce the cost of a drug to the NHS and improved access to more effective drugs that otherwise might have not been available in the NHS as a result of a negative decision by the National Institute of health and Care Excellence (NICE) or the Scottish Medicines Consortium (SMC).

The Government's view on VBP is that it will "encourage the development of breakthrough drugs addressing areas of significant unmet need. A much closer link between the price the NHS pays and the value the medicine delivers is needed, sending a powerful signal about the areas that the pharmaceutical industry should target for development" (Department of Health, 2010). More specifically, this new regime based on "value" will incentivise companies to undertake Research \& Development to find the most effective treatments NHS patients need (Towse, 2007). The principal expectations are that in the short run technologies will be adopted for the use in the NHS only at prices that ensure that the expected health benefit exceeds the health predicted to be displaced elsewhere in the NHS due to additional costs. In the longer run, prices based on value to the NHS will provide a clear signal and incentives to invest in the development of technologies which are more likely to demonstrate their cost-effectiveness (Claxton, 2007).

\section{Objectives and Drivers of VBP}

VBP aims to address a broader set of objectives than the current system. First of all, it should stimulate and promote innovation to areas with greater unmet need, and ensure value for money and best use of NHS resources. 
Moreover, it should improve the process for assessing new medicines, ensuring transparency, predictability and timely decision-making, as well as improving outcomes for patients through better access to effective medicines (Department of Health, 2010).

At first place, the UK Government proposed to include three aspects in the value of a new drug; therapeutic innovation and improvement, wider societal benefits, and burden of illness (Department of Health, 2010). It is explicitly indicated that value will entail a number of elements: the improvement in health resulting from the treatment, measured by QALYs gained; the burden of illness, encompassing the severity of ill health and the level of "unmet need"; some measure of "innovativeness"; and "wider societal benefits" (Sussex et al., 2013).

Therapeutic improvement and innovation (TII) was considered to be a key driver in the value of new drugs; however, there is no agreed-upon definition of what TII is and which factors constitute its measurement. After a lot of criticism that TII accepted, in the grounds of double counting the benefits already valued, the DoH, in June 2013, announced that VBP will not include a further weighting for TII in order to ensure that innovation is rewarded only when the technology's use brings extra value.

Another significant factor included in the value of the new treatment was the wider societal benefits. The DoH in June 2013 stated that the methods for value assessment of branded medicines under VBP should include a proportionate system for taking into account the WSB. Specifically, the benefits and costs not borne by the NHS and hence not fall on the health care system such as the indirect effects external to patients (Claxton et al., 2010) should be considered under VBP. However, in January 2014 the DoH announced that WSB will not be included in the assessment of VBP.

As a result, the VBP will be constituted only by the BoI; a simple system of weighting that appropriately reflects the differential value of treatment for the most serious conditions. The term "burden" simply means the negative impact of illness. Alternatively, burden can be defined as the "cost" of illness where that cost is understood to encompass the full social cost of illness, including subjective, hard-to-quantify elements as well as objective more rapidly measures elements (McGuire et al., 2002).

The DoH explicitly mentions that the most important factors contributing to the measurement of BoI would be the severity of the condition and the level of unmet need (Department of Health, 2010). It is not always clear what is meant by severity, although the most popular method in literature is to define severity in terms of the patient's pre-treatment health state (Shah, 2009). For this reason, the VBP consultation document suggests that severity may be defined as health without treatment (in terms of QALYs) and could reflect also the condition which leads to premature death or serious morbidity. Furthermore, the consultation suggests that unmet need could be reflected by the degree to which there are existing treatments. In particular, significant unmet need can be characterised by a high QALY loss when there is no effective treatment (Shah \& Devlin, 2012). 


\section{Measurement of BoI}

Two categorisations of diseases exist in the litearture; the first being the World Health Organisation's (WHO) Global Burden of Disease (GBD) measured with DALYs, and the second from the CHE University of York assessing BoI measured by the QALYs lost.

\section{BoI measured with DALYs}

The DALY measurement unit is used to quantify the burden of diseases, injuries and risk factors on human populations, and is grounded on cogent economic and ethical health care (Murrey \& Acharya, 1997). The DALY extends the concept of "healthy" life lost due to premature death to include equivalent years of "healthy" life lost by virtue of being in states of poor health or disability. As a result, one DALY can be thought of as one lost year of "healthy" life. The sum of those DALYs across the population, or the burden of disease can be thought of as a measurement of the gap between current health status and an ideal health situation where the entire population lives to an advanced age, free of disease and disability (WHO, 2008).

\section{BoI measured as QALYs lost}

Alternatively, BoI might be measured using the QALY loss suffered by patients under current treatments. Claxton et al. (2013) refer to the burden of illness as total QALYs lost due to premature death and during disease while alive or disability. This argument is based on the notion that all NHS activity and expenditure not only influence mortality but also affects the quality of life while alive and experiencing a disease. Moreover, proportionate effects on burden from estimated effects on life years were applied in order to measure the QALY burden for all Program Budgeting Categories (PBCs). The total QALY burden of disease for a population with the disease in a particular year includes: (i) the years of life lost due to all the disease related mortality that occurs in the population over their remaining duration of disease and (ii) the reduction in quality of life while alive also for their remaining disease duration (Claxton et al., 2013).

\section{Practical Applications}

Case studies were conducted with respect to selected old nonrecommended and optimised NICE submissions with an investigation into how these particular decisions might differ under VBP.

Each submission's disease area was matched with the corresponding total number of DALYs and QALYs lost as reported in Table 1. This process was made in order to construct a list categorising the diseases into their burden, i.e. higher, medium or lower burden. Table 1 demonstrates the total number of DALYs and QALYs lost for each disease area under some important assumptions. 
First of all, it is assumed that the total number of DALYs for a disease is the same irrespectively of its metastatic or stable, severe or mild, advanced or early staged and chronic or non-chronic condition. In addition, particularly for the NICE TA189, hepatocellular carcinoma (HCC) is a dominant form of liver cancer, accounting for 80-90\% of liver cancer cases (Marrero et al., 2002).Thus it is assumed that the total number of DALYs for liver cancer resembles the total number of DALYs for HCC. Finally, in NICE TA 201, it is assumed that the total number of DALYs do not change for children aged 6-11 to those aged 0-14 (subgroup data source as referred in the WHO's GBD report).

Table 1. Total Number of DALYs and QALYs lost for Each Disease Area Relevant to the selected NICE TAs

\begin{tabular}{|c|c|c|c|c|c|}
\hline $\begin{array}{c}\text { NICE } \\
\text { TA }\end{array}$ & $\begin{array}{l}\text { Population } \\
\text { Indication }\end{array}$ & $\begin{array}{c}\text { Disease } \\
\text { category }\end{array}$ & $\begin{array}{c}\text { Total } \\
\text { DALYs* }\end{array}$ & PBCs & $\begin{array}{c}\text { QALY } \\
\text { burden* }\end{array}$ \\
\hline TA 271 & NA & $\begin{array}{l}\text { Macular } \\
\text { degeneration } \\
\text { and other }\end{array}$ & 83,000 & 8. Vision & 0.05 \\
\hline TA 263 & NA & Breast cancer & 147,000 & $\begin{array}{l}\text { 2. Cancers } \\
\text { and tumours }\end{array}$ & 2.93 \\
\hline TA 255 & NA & Prostate cancer & 63,000 & $\begin{array}{l}\text { 2. Cancers } \\
\text { and tumours }\end{array}$ & 2.93 \\
\hline TA 234 & NA & $\begin{array}{c}\text { Rheumatoid } \\
\text { Arthritis }\end{array}$ & 62,000 & $\begin{array}{l}\text { 15. Musculo } \\
\text { skeletal } \\
\text { system }\end{array}$ & 0.12 \\
\hline TA 222 & women & Ovarian cancer & 4,500 & $\begin{array}{l}\text { 2. Cancers } \\
\text { and tumours }\end{array}$ & 2.93 \\
\hline TA 217 & NA & $\begin{array}{l}\text { Alzheimer's } \\
\text { disease }\end{array}$ & 303,000 & $\begin{array}{l}\text { 5. Mental } \\
\text { Health }\end{array}$ & 0.12 \\
\hline TA 212 & NA & $\begin{array}{l}\text { Colon and } \\
\text { rectum cancers }\end{array}$ & 139,000 & $\begin{array}{l}\text { 2. Cancers } \\
\text { and tumours }\end{array}$ & 2.93 \\
\hline TA 208 & NA & Stomach cancer & 43,000 & $\begin{array}{l}\text { 2. Cancers } \\
\text { and tumours }\end{array}$ & 2.93 \\
\hline TA 201 & $\begin{array}{l}\text { children } \\
\text { aged 6-11 }\end{array}$ & Asthma & 65,000 & $\begin{array}{c}11 . \\
\text { Respiratory } \\
\text { system }\end{array}$ & 0.09 \\
\hline TA 189 & NA & Liver cancer & 21,000 & $\begin{array}{l}\text { 2. Cancers } \\
\text { and tumours }\end{array}$ & 2.93 \\
\hline TA 154 & NA & Hepatitis B & 1,000 & $\begin{array}{l}\text { 1. Infectious } \\
\text { diseases }\end{array}$ & 0.31 \\
\hline TA 127 & NA & $\begin{array}{l}\text { Multiple } \\
\text { Sclerosis }\end{array}$ & 28,000 & $\begin{array}{c}7 . \\
\text { Neurological }\end{array}$ & 0.13 \\
\hline TA 119 & NA & Leukaemia & 40,000 & $\begin{array}{l}\text { 3. Disorders } \\
\text { of blood }\end{array}$ & 0.06 \\
\hline
\end{tabular}

*Total DALYs as indicated by the WHO 2004 report and QALY burden as illustrated in Claxton et al. 2013 
Vol. 1, No. 2 Alexiou: How the Assessment of Burden of Illness might change NICE Decisions...

\section{Results}

The crucial part of this analysis was to categorise the diseases relevant to the selected NICE Technology Appraisals (TAs) into higher, medium and lower burden (Table 2 and Table 3 ). This classification was conducted via the aforementioned approaches; the use of DALYs and the use of QALYs lost. The purpose of this classification was to identify the main and leading causes of burden of illness in order to categorise NICE TAs.

The rationale behind the classification of disease into higher, medium and lower burden lies in the grounds of the number of total DALYs and QALYs lost.

Table 2. Classification of the selected Diseases measured as DALYs

\begin{tabular}{|c|c|}
\hline Higher & $>300,001$ DALYs \\
\hline Medium & $<300,000$ DALYs and $>60,001$ DALYs \\
\hline Lower & $<60,000$ DALYs \\
\hline
\end{tabular}

Table 3. Classification of the selected Diseases Measures by QALYs Lost

\begin{tabular}{|l|l|}
\hline Higher & $>2$ QALYs lost \\
\hline Medium & $\begin{array}{l}<1.99 \text { QALYs lost and >0.11 QALYs } \\
\text { lost }\end{array}$ \\
\hline Lower & $<0.10$ QALYs lost \\
\hline
\end{tabular}

Figure 1. BoI Classification into Higher, Medium and Lower measured as $D A L Y S$

\section{BoI classification (DALYs)}

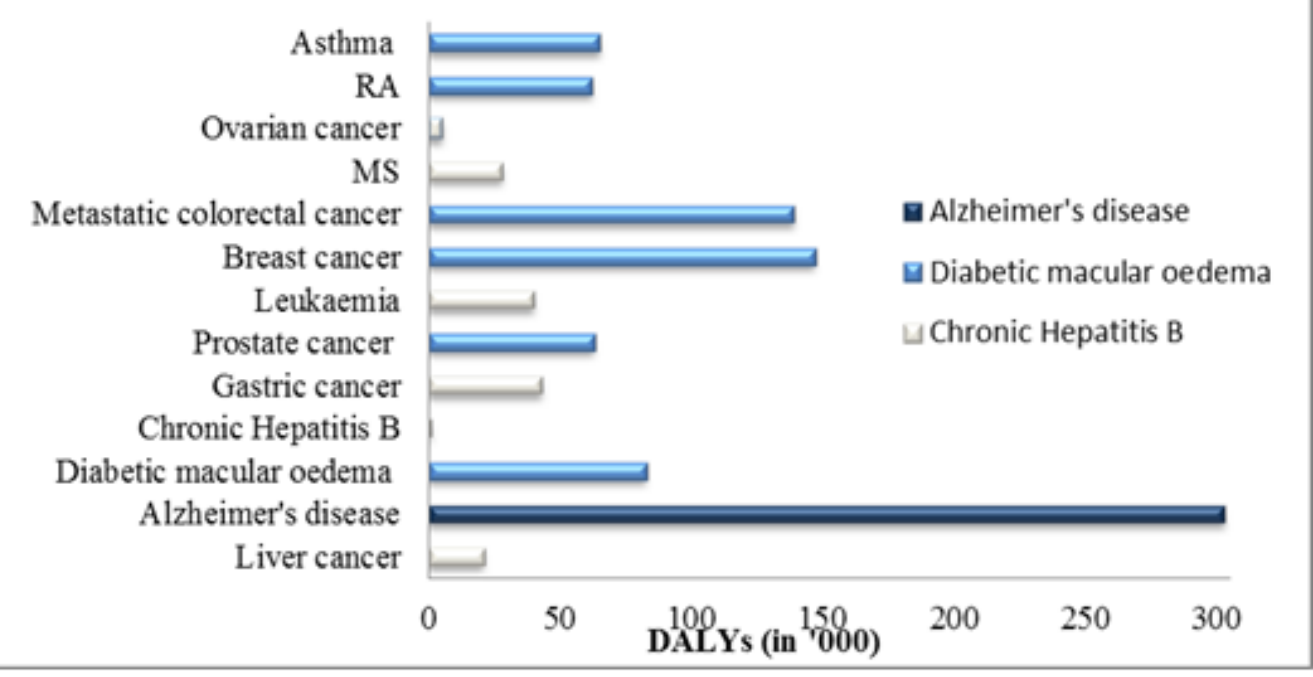

According to Figure 1, it is evident that the leading cause of burden of illness is Alzheimer's disease providing 303,000 DALYs. On the other hand, 
the lowest BoI defined by DALYs is represented by Hepatitis B with the total number of years lived with Hepatitis $B$ and the years lost due to premature mortality for the UK population to be 1,000 .

Additionally, the DALYs per person were calculated taking into account the incidence rates of each disease displayed in the manufacturer's submission. For example, in England and Wales 700 patients per year are diagnosed and identified as eligible for treatment of Hepatitis B (Shepherd et al., 2006). As a result, $1,000 / 700=1.43 \mathrm{DALY}$ s/person indicating that 1.43 years people spent with Hepatitis B. Similarly, according to the Cancer Research UK, the incidence rates of prostate cancer in England and Wales is estimated 36,105. Therefore, 1.745 years people spent with prostate cancer, which reveals the medium burden incidence that this disease represents compared to Hepatitis C which offers lower burden.

Now considering the QALYs lost measure, Figure 2 presents categorisation into higher, medium and lower BoI, drawing upon QALYs lost from Claxton et al, 2013. It is assumed that all cancer diseases offer the same amount of QALYs lost irrespectively of their type (PBCs do not differentiate cancer disease separately) and thus are placed in the higher burden of illness category. This is due to the fact that the cancer diseases have a bigger impact on deaths comparing to asthma or macular oedema for example with 0.09 and 0.05 QALYs lost, respectively. In cancer, 2.93 QALYs lost indicate that each cancer patient will lose 2.93 years of their full health due to this disease. This is considered equivalent to 5.86 years at half health.

Figure 2. BoI Classification into High, Medium and Low measured as QALYS Lost

\section{BoI classification (QALYs lost)}

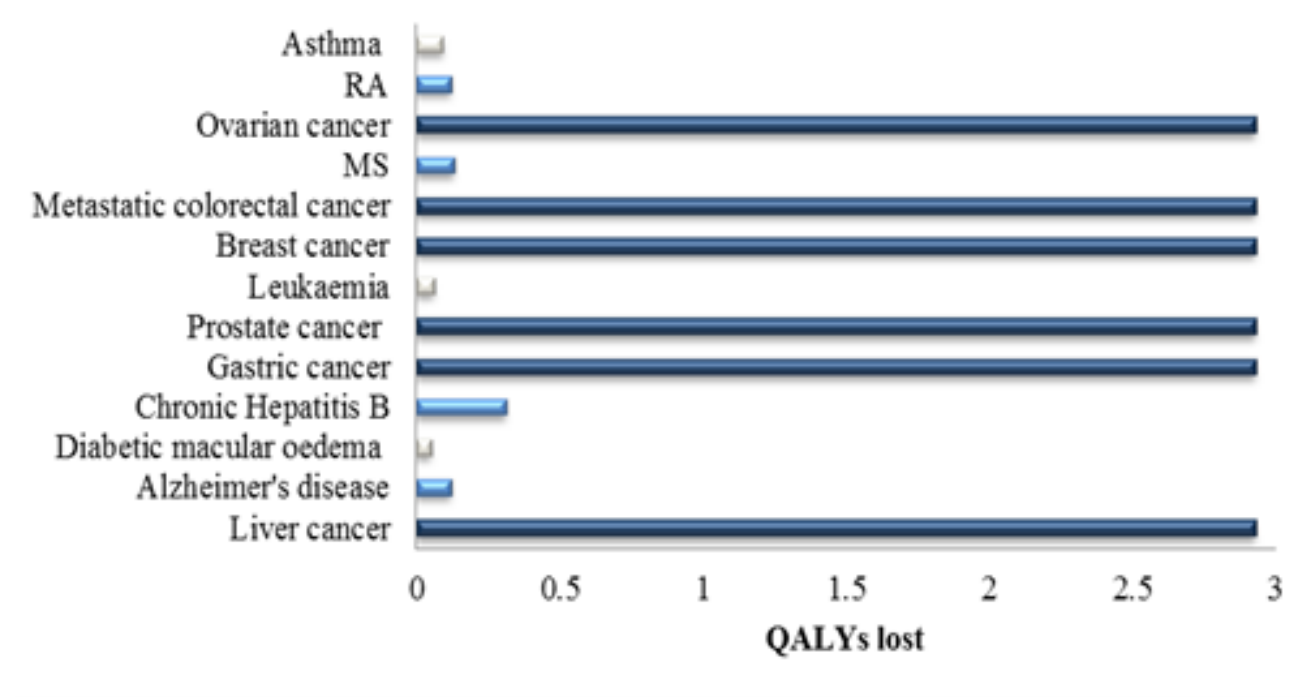

Comparing the alternate classification measures using DALYs and QALYs lost, it is apparent that the results differ dependent on BoI measurement tool. 
The main difference is that HCC is classified into the high burden under the QALYs lost, whereas under DALYs is classified into low burden of disease. While QALYs are estimated using mortality data, DALYs are estimated using life expectancy, and this may lead to differences in the estimation of DALYs and QALYs lost.

RA remains in the medium burden category and leukaemia in the low burden class. However, these are exceptions as there are few such cases where a disease remains in the same category using both measurement tools. With all these considerations it is very difficult to draw any conclusion of which measure is the best to use or how the categories of burden differ and it is clear that the choice of categorisation plays significant role in classifying diseases into a pre-determined BoI category. An attempt to combine both measurement tools so as to provide a unique classification of BoI was made as illustrated in Table 4. But is the burden of illness under VBP a major driver in order to change NICE appraisals?

With respect to the change in NICE decisions under VBP, the following NICE TAs were considered: TA 271 (macular oedema), TA 255 (prostate cancer), TA 263 (breast cancer), TA 222 (ovarian cancer), TA 234 (RA), TA 212 (colorectal cancer), TA 189 (HCC) and TA 154 (leukaemia).

Table 4. A Unique BoI Classification used for Analysis

\begin{tabular}{|c|c|c|c|}
\hline TAs-Diseases & DALYs & QALYs & Unique class \\
\hline 271-Macular Oedema & Medium & Low & Medium to Low \\
\hline 255-Prostate Cancer & Medium & High & Medium to High \\
\hline 263-Breast Cancer & Medium & High & Medium to High \\
\hline 222-Ovarian Cancer & Low & High & Medium \\
\hline 234-RA & Medium & Medium & Medium \\
\hline $\begin{array}{c}\text { 212-Colorectal } \\
\text { Cancer }\end{array}$ & Medium & High & Medium to High \\
\hline 189-HCC & Low & Medium & Medium to Low \\
\hline 154-Hepatitis B & Low & Medium & Medium to Low \\
\hline 119-Leukaemia & Low & Low & Low \\
\hline
\end{tabular}

In order to draw a conclusion about the NICE recommendations it is essential to think both the cost and the clinical effectiveness along with the BoI assessment for each disease. Necessary questions have to be made so as to decide if NICE decisions would change. Is the intervention clinically and cost effective? If yes, in which burden category is the disease placed? If it is classified in the high or medium to high burden, should a higher threshold be considered? Following, Table 5 illustrates all the alternative combinations and the rules for making the decisions for recommendations. 
Table 5. Rules for making the Decisions when combining the Cost and Clinical Effectiveness with the BoI Assessment

\begin{tabular}{|c|c|c|c|c|}
\hline Pathways & $\begin{array}{c}\text { Cost } \\
\text { effectiveness }\end{array}$ & $\begin{array}{c}\text { Clinical } \\
\text { effectiveness }\end{array}$ & $\begin{array}{c}\text { BoI } \\
\text { categorisation }\end{array}$ & $\begin{array}{c}\text { Decision for } \\
\text { recommendation }\end{array}$ \\
\hline 1 & Yes & Yes & Low & Recommended \\
\hline 2 & Yes & Yes & Medium to Low & Recommended \\
\hline 3 & Yes & Yes & Medium & Recommended \\
\hline 4 & Yes & Yes & $\begin{array}{l}\text { Medium to } \\
\text { High }\end{array}$ & Recommended \\
\hline 5 & Yes & No & Low & Not Recommended \\
\hline 6 & Yes & No & Medium to Low & Not Recommended \\
\hline 7 & Yes & No & Medium & $\begin{array}{c}\text { Recommended } \\
\text { when new } \\
\text { evidence available }\end{array}$ \\
\hline 8 & Yes & No & $\begin{array}{l}\text { Medium to } \\
\text { High }\end{array}$ & $\begin{array}{c}\text { Recommended } \\
\text { when new } \\
\text { evidence available }\end{array}$ \\
\hline 9 & No & Yes & Low & Not Recommended \\
\hline 10 & No & Yes & Medium to Low & Not Recommended \\
\hline 11 & No & Yes & Medium & $\begin{array}{l}\text { Recommended } \\
\text { with alterations }\end{array}$ \\
\hline 12 & No & Yes & $\begin{array}{l}\text { Medium to } \\
\text { High }\end{array}$ & $\begin{array}{l}\text { Recommended } \\
\text { with alterations }\end{array}$ \\
\hline 13 & No & No & Low & Not Recommended \\
\hline 14 & No & No & Medium to Low & Not Recommended \\
\hline 15 & No & No & Medium & Not Recommended \\
\hline 16 & No & No & $\begin{array}{l}\text { Medium to } \\
\text { High }\end{array}$ & Not Recommended \\
\hline
\end{tabular}

Apart from the aforementioned rules, uncertainty still exists in the actual value of the threshold. As a result, it is vital to mention that if the ICER of an intervention is between the range of $£ 20,000$ and $£ 80,000$, as this upper bound is an implicit threshold in the Netherlands (Bending \& Smith, 2012), the disease is placed in a high burden category, and it is clinically and cost effective, then a recommended decision might be the most optimal.

NICE TA271 was a submission for the treatment of macular oedema. The appraisal committee concluded that the intervention demonstrated greater efficacy to the comparator indicating that the intervention is indeed clinically effective. However, the treatment is not cost effective with the evidence review group (ERG) commenting that the ICER is at least $£ 47,600$. Considering the BoI classification, macular oedema is placed in the medium to low category. As a result, the decision, under the assessment of BoI, would not change since a higher threshold is not required to be considered at this particular case (medium to low BoI) and thus the intervention remains cost ineffective.

Furthermore, similarly to the previous TA, NICE TA255 was a submission for the treatment of prostate cancer. NICE appraisal committee concluded that the intervention is clinically effective due to the fact that the majority of the evidence presented was robust and clear, whereas it is not cost effective as the 
ICER is $£ 75,000$. Taking into account the fact that prostate cancer is placed in the medium to high burden class, the intervention might have been recommended with some potential alterations like a price decrease by the manufacturer, or an increase in the threshold.

NICE TA 263 for breast cancer and TA222 for ovarian cancer show that the assessment of BoI does not play any significant role for the reimbursement process. Both treatments are not clinically effective due to the fact uncertainties in the clinical evidence were presented with insufficiently robust results. From the cost effectiveness perspective, both ICERs are greatly more than the NICE's typical upper limit (£30,000/QALY) and even though the diseases are positioned in medium to high and medium BoI, respectively, the decision might not alter until new evidence come to light. On the other side, when a treatment is both cost and clinically effective but other factors might drive the non-recommended decision, and the disease is categorised into medium to high or medium burden, as it is the case for NICE TA234 for the treatment of RA, then the NICE decision might change to recommended.

Considering NICE TA212 for the treatment of colorectal cancer, the decision could not have changed under VBP and the assessment of BoI because the ICER is placed far beyond the upper bound of $£ 30,000$, with no clinically robust data, even when the disease corresponds to medium to high burden. Furthermore, hepatocellular carcinoma (NICE TA189) is categorised into medium burden. The committee stated that the clinical trials used as evidence in this appraisal are clinically meaningful and the treatment is clinically effective, although the intervention is not cost effective. A non-recommended decision was applied even though the treatment for HCC had met the NICE special case criteria of a life-extending, end-of-life treatment, and that the evidence presented was supported by robust data. Consequently, this decision might have been recommended with some adjustments in the cost effectiveness of the intervention with a higher threshold, for example lowering the price of the drug or considering a Patient Access Scheme (PAS).

Last but not least, in NICE TA154 and TA119 for the treatments of hepatitis B and leukaemia respectively, the ICERs are between the range of $£ 20,000$ and $£ 30,000$ and both diseases are categorised as medium to low or low burden. In some subgroups in both cases, the interventions are more clinically effective than the comparator, although uncertainty surrounded this efficacy because of unclear data sources. Due to the fact that the disease areas are classified as low or medium to low BoI, the non-recommended decision might not change until this data source uncertainty is eliminated or new evidence comes to light.

\section{Discussions and Conclusions}

VBP is a new system due to be implemented in 2014. With the luck of clarity that currently exists over the specifics and practical application of the specifics, this paper selected BoI as a key driver of value and categorised 
disease areas by BoI accordingly with a subsequent hypothetical analysis of previous NICE technology appraisals, driven by value as defined by BoI categorisation.

It may be criticised that other aspects rather than the measurement of health gains are not fully captured by NICE appraisals; for example, some aspects of social value or even some aspects of the burden of each disease. VBP will try to give an appropriate weight to all those factors that might be of importance and ought to be included in the process of NICE appraisals. However, uncertainty still exists in the context of a proper definition of the BoI and its appropriate measurement tool.

This research provides a comprehensive overview of VBP and an attempt to assess BoI as the key driver to any decision taken by NICE. The main objective of this retrospective analysis was to address the question of how VBP might change old non-recommended and optimised NICE decisions. However, one of the main limitations of this research is the uncertainty reflecting any NICE decision under VBP in the context of a proper definition of BoI and a unique measurement tool so as BoI to be aptly quantified and incorporated into cost effectiveness analyses.

The main finding of the practical application of VBP and the assessment of BoI as a key component is that no conclusion can be drawn before the formal decisions are published by NICE for VBP. A categorisation of the diseases into higher, medium, and lower burden was attempted and it was evident that the decisions differed with respect to the different measurement tool that was used. In some cases BoI played little role into the assessment of NICE decisions due to the fact that clinical effectiveness was considered a more important factor. In other cases, where the ICER was bounded into the recommended range and the disease area was found to be of medium to high or medium burden, the nonrecommended or optimised decisions might have changed under VBP.

The most significant aspect for NICE to deal with, is to develop a classification and a proper and specific definition of BoI otherwise BoI becomes a meaningless aspect of VBP. Another limitation of the evidence used in this paper is that the WHO data which is out of date and the measurement of DALYs is not a key metric recommended by NICE. UK specific data is important as prevalence and thus overall disease BoI differs between countries. Last but not least, luck for subgroup disease classification was identified, i.e. particular types of cancer, or particular subgroups of patients such as children within a disease area.

However, one thing can be taken as granted. It is vital to prioritise disease areas and customise the criteria under which NICE decisions are taken. Reassessing the cost effectiveness analyses of the interventions might be triggered when new evidence becomes available. As a result, VBP may ask for additional requirements on the amount and the quality of evidence requested. 
Vol. 1, No. 2 Alexiou: How the Assessment of Burden of Illness might change NICE Decisions...

\section{References}

Association of the British Pharmaceutical Industry, 2011. ABPI. [Online] Available at: http://www.abpi.org.uk/our-work/policy-parliamentary/Documents/abpi- vbpresponse-formal-submission.pdf [Accessed 29 July 2013].

Bending, M., \& Smith, A. 2012. Value and the multiple criteria used in OECD countries' medicine reimbursement decision-making processes using health economics evidence.Value in Health, Volume 15(7), pp. A310.

Claxton, K., Martin, S., Soares, M., Rice, N., Spackman, E., Hinde, S., Devlin, N., Smith, P.C. \& Sculpher, M. 2013. Methods for the Estimation of the NICE Cost Effectiveness Threshold, York: Centre for Health Economics, The University of York. CHE Research Paper 81.

Claxton, K., Walker, S., Palmer, S. \& Sulpher, M., 2010. Appropriate Perspective for Health Care Decisions, York: Centre for Health Economics, The University of York. CHE Research Paper 54.

Claxton, K., 2007. OFT, VBP: QED?. Health Economics, Volume 16, pp. 545-558.

Claxton, K., Briggs, A., Buxton, M., Culyer, A., McCabe, C., Walker, S. \& Sculpher, M. 2008. Value based pricing for NHS drugs: an opportunity not to be missed?. BMJ, Volume 336, pp. 251-254.

Claxton, K., Sculpher, M. \& Caroll, S., 2011. Value-based pricing for pharmaceuticals: Its role, specification and prospects in a newly developed NHS., York: Centre of Health Economics, University of York. CHE Research Paper 60.

Department of Health., 2010. A new value-based approach to the pricing of branded medicines: a consultation, London: Department of Health.

Department of Health., 2012. Pharmaceutical Price Regulation Scheme: Eleventh Report to Parliament., London: Department of Health.

Garner, S., 2010. How does NICE value Innovation?. Drug Development Research , Volume 71, pp. 449-456.

Hughes, D. A., 2011. Value-Based Pricing; Incentive for Innovation or Zero Net Benefit?. Pharmacoeconomics, 29(9), pp. 731-735.

Institute for Health Metrics and Evaluation. The Global Burden of Disease: Generating Evidence, Guiding Policy. Seattle, WA: IHME, 2013 [Online] Available at: http://www.healthmetricsandevaluation.org/sites/default/files/policy report/201 1 /GBDGenerating\%20Evidence_Guiding\%20Policy\%20FINAL.pdf [Accessed 27 August 2013].

Marrero, A. J., Fontana, J.A., Su, G.L., Conjeevaram, H.S., Emick, D.M. \& Lok, A. 2002. NAFLD may be a common underlying liver cancer in patients with hepatocellular carcinoma in the United States. Hepatology, 36(6), pp. 1349-1354.

McCabe, C., Claxton, K. \& Culyer, A. J. 2008. The NICE cost-effectiveness threshold, what is and what that means. Pharmacoeconomics, 26(9), pp. 733-744.

McGuire, T., Wells, B.K., Bruce, M.L., Miranda, J., Scheffler, R., Durham, M., Ford, D.E. \& Lewis, L. 2002. Burden of Illness. Mental Health Sercices Research, 4(4), pp. 179-185.

National Institute of Health and Clinical Excellence., March 2011. Value Based Pricing: consultation response, s.l.: NICE.

Office of Health Economics, 2011. The Office of Health Economics response to the Department of Health's consultation, London: Office of Health Economics.

Office of Fair Trading., February 2007. The Pharmaceutical Price Regulation Scheme: an OFT market study., London: Office of Fair Trading. 
Shah, K. \& Devlin, N., December 2012. Understanding Social Preferences regarding addressing unmet need and severity, London: Office of Health Economics. Research Paper 12/05.

Shah, K. K., 2009. Severity of illness and priority setting in healthcare: A review of the literature. Health Policy, Volume 93, pp. 77-84.

Shepherd, J., Jones, J., Takeda, A., Davidson, P. \& Price, A. 2006. Adefovir, dipivoxil and pegylated interferon alfa-2a for the treatment of chronic hepatitis B: a systematic review and economic evaluation. Health Technology Assessment, 10(28), pp. iii-xiv, 1.

Sussex, J., Towse, A. \& Devlin, N., 2013. Operationalizing Value-Based Pricing of Medicines; A Taxonomy of Approaches. Pharmacoeconomics, Volume 31, pp.1-10.

Syrett, K., 2012. Pricing New Medicines in the UK: "Price is what you Pay, Value is what you Get?". Law, Innovation and Technology, 4(2), pp. 185-211.

Thornton, S., 2007. Drug price reform in the UK: Debunking the myths.. Health Economics, 16(10), pp. 981-992.

Towse, A., 2007. If it aint's broke, don't price fix it: the OFT and the press. Health Economics, Volume 16, pp. 653-665.

Webb, D. \& Walker, A., 2007. Value-based pricing of drugs in the UK. Lancet, 369(9571), pp. 1415-1416.

World Health Organisation, 2008. The Global Burden of Disease; 2004 Update, Geneva: World Health Organisation. 
